\title{
A ETOCRACIA DE HOLBACH: POLÍTICA E MORAL NUMA PERSPECTIVA MATERIALISTA
}

\author{
Fábio Rodrigues de Ávila ${ }^{1}$ \\ Universidade Federal de São Paulo
}

\begin{abstract}
Resumo: Em suas últimas obras, Barão de Holbach elabora um sistema moral e político propondo uma análise da natureza humana a partir de sua filosofia materialista. Ao investigar as idiossincrasias humanas, ele expõe uma concepção de paixão que se liga à tradição espinosista, na qual as paixões são tomadas por sentimentos de amor ou ódio pelos objetos que afetam a sensibilidade, de acordo com as impressões de prazer e dor que esses objetos causam. Assim, um objeto que proporcione prazer nos sentidos desperta uma sensação de amor, que impele o homem a buscá-lo. Igualmente, um objeto que proporcione uma sensação dolorosa despertará 0 ódio, que fará com que esse objeto seja repelido e evitado. Esse mecanismo funciona tanto com relação aos objetos inanimados que servem para satisfazer as necessidades humanas, como também para dar origem às relações sociais entre os indivíduos. Por isso 0 autor sugere alguns princípios morais como deveres, dos quais a virtude seria seu fundamento. Logo, ações como a temperança, a prudência, a compaixão ou a tolerância, que tem por base a alegria e o prazer, funcionam como instrumentos de realização das relações sociais. Todavia, sentimentos como a inveja, o orgulho, a avareza ou o fanatismo tornam essas relações nocivas e contribuem para que os homens sejam inimigos uns dos outros. Desse modo, para que uma sociedade seja estável, Holbach sugere que as paixões derivadas das impressões de prazer e dos impulsos de amor sejam o laço que possibilita às relações humanas tornarem a vida coletiva agradável e desejada. A proposta dessa tese é analisar 0 pensamento político que emerge dessa perspectiva de moral, com base principalmente nas últimas obras de Holbach, quais sejam, A Moral Universal, La Politique Naturelle e Système Social. Nosso objetivo é investigar a relação que existe em sua filosofia entre três operadores morais: as paixões que servem como instrumentos para a sociabilidade, 0 interesse que é o motor das ações e a utilidade enquanto vislumbre dos objetos que podem ou não satisfazer as necessidades humanas. A partir destes operadores, que constituem um mecanismo que corresponde à natureza material do homem, temos o alicerce da moral e da vida política. Compreendendo a Natureza enquanto complexo de moléculas que interagem entre si a partir de suas qualidades, a sociedade é entendida nessa perspectiva. Pretendemos assim investigar o homem em seus aspectos psicológicos e sociais, e as instituições que fomentam suas relações, para enfim analisar como é possível, a partir dessa visão determinista e reducionista do materialismo, fundamentar um sistema moral e político de fato.
\end{abstract}

Palavras-chave: Moral. Materialismo. Politica. Natureza Humana. Paixões.

1 Doutorando em Filosofia. fabioc12@hotmail.com

\section{Blucher}


Fábio Rodrigues de Ávila

Holbach's ethocratie: Moral and politics from a materialistic perspective

Abstract: In his later works, the Enlightenment philosopher Baron d'Holbach elaborates a moral and political system proposing an analysis of human nature from his materialistic philosophy. He lists a number of moral qualities which serve as principles of virtue and sociability, while pointing out the vices that are harmful to social life. He organizes a deep investigation of human idiosyncrasies and exposes a conception of passion that ties in with the Spinozian tradition, in which passions are overwhelmed by feelings of love or hate for objects that affect sensibility, according to the impressions of pleasure and pain which those objects cause. Thus, an object that provides pleasure in the senses arouses a feeling of love, which impels man to seek it. In the same way, an object that provides a painful sensation will arouse hate, which in turn will generate repulsion and avoidance of such object. This mechanism works in relation to both inanimate objects serving to satisfy human needs and the social relations between individuals arisen thereby. Thereupon, the author suggests some moral principles as duties, of which virtue would be the foundation. Therefore, actions such as temperance, prudence, compassion or tolerance, which are based on joy and pleasure, behave as instruments whereby social relationships take place. On the other hand, feelings such as envy, pride, avarice, or fanaticism make those relationships harmful and contribute to men being enemies to each other. Thus, for a society to be stable, Holbach suggests that the passions derived from the impressions of pleasure and the impulses of love are the liaison which turns the human collective life into a pleasant and desirable one. The purpose of this article is to analyze the political thought that emerges from this perspective of morality, based mainly on the later works of Holbach, namely The Universal Moral, La Politique Naturelle, and Système Social. Our aim is to investigate the relation between three moral operators in his philosophy: passions as instruments for sociability, interest as the moving force of actions, and utility as the prospective look upon objects that may or may not satisfy human needs. From these operators, which compose a mechanism that corresponds to the material nature of man, we have the foundation of morality and political life. Through the consideration of Nature as a complex of molecules that interact with each other from their qualities, society is understood in this perspective. Therefore, we intend to investigate man in his psychological and social aspects, as well as the institutions that foment his relations, in order to analyze how it is possible, based on this deterministic and reductionist view of materialism, to ground a really moral and political system.

Keywords: Moral. Materialism. Politics. Human Nature. Passions. 


\section{Introdução ao pensamento de Holbach:}

0 barão de Holbach, importante, porém pouco conhecido filósofo iluminista, que pertence à corrente materialista do século XVIII, além de ter sido um grande colaborador da Enciclopédia de Diderot e D'Alembert, é mais lembrado pela sua obra Sistema da Natureza (1770), considerada uma "máquina de guerra" 2 no encarniçado debate das Luzes na luta dos philosophes contra 0 poder hegemônico do pensamento teológico-metafísico cristão tanto quanto da supremacia da monarquia absolutista. Nesta obra, encontramos uma crítica contundente ao pensamento filosófico tradicional, que tem em seu âmago a tradição platônico-cristã - com seu dualismo metafísico e teológico, que parte da distinção entre matéria e espírito -, além também de formular um sistema ontológico monista que compreende a Natureza ${ }^{3}$ e toda a realidade existente como um complexo de matéria que se organiza a partir de seus atributos, conforme suas qualidades e movimentos. Ele diz:

0 universo, essa vasta reunião de tudo aquilo que existe, não nos oferece em toda parte senão a matéria e o movimento: seu conjunto não nos mostra senão uma cadeia imensa e ininterrupta de causas e efeitos [...]. Assim, a natureza, em sua significação mais extensa, é o grande todo que resulta da reunião das diferentes matérias, de suas diferentes combinações e dos diferentes movimentos que nós vemos no universo (HOLBACH, 2010, p.40).

\footnotetext{
${ }^{2}$ Usando a expressão de Gilles Deleuze.

${ }^{3}$ Utilizaremos aqui o termo Natureza com maiúscula para designar a ideia de Holbach de Todo. Ele próprio trata-se de esclarecer ao leitor de seu Sistema da Natureza a respeito do uso dessa palavra, que não deve ser confundida com um ser primordial, personificado, que possua vontade e liberdade de ação próprias, mas antes uma palavra que designa o conjunto dos seres existentes: "Depois de ter fixado o sentido que deve ser dado à palavra natureza, creio dever advertir o leitor, de uma vez por todas que, quando no decorrer desta obra, digo que a natureza produz um efeito, não pretendo de modo algum personificar essa natureza, que é um ser abstrato. Entendo que o efeito do qual eu falo é o resultado necessário das propriedades de algum dos seres que compõem o grande conjunto que nós vemos" (HOLBACH, 2010, p. 41).
} 


\section{Fábio Rodrigues de Ávila}

O Sistema da Natureza, sendo propositadamente um texto combativo, possui um teor filosófico mais voltado para as questões teológicas e metafísicas, adquirindo um caráter específico: busca desconstruir o pensamento filosófico tradicional, que tem em sua base a dualidade matéria/espírito e todo o conhecimento humano dela derivado. Seu objetivo principal é enfrentar o dogmatismo religioso que reina nos debates acadêmicos e nos salões filosóficos, e que dita as regras das ideias morais e políticas de seu tempo.

Contudo, em suas obras posteriores e menos conhecidas, Holbach se propõe a um objetivo mais preciso: erigir um sistema moral e político com base em princípios derivados da sua concepção materialista da Natureza. Ou seja, o que é apenas esboçado no Sistema da Natureza enquanto apresentação de uma filosofia política naturalista, em suas últimas obras, La Politique Naturelle (1773), Système Social (1773), Ethocratie (1776) e La Morale Universelle (1776), esse projeto é levado a cabo de forma mais contundente e rigorosa. Nestas obras, seu objetivo é desenvolver de forma mais sistemática as propostas já apresentadas no Sistema da Natureza, quais sejam: (1) estabelecer uma crítica à moral tradicional e às suas instituições, que segundo ele, são nocivas para a vida em sociedade; (2) apresentar uma visão do homem de acordo com sua essência verdadeira, que é a matéria e seus movimentos; e (3) propor um sistema moral e político eudemonista, no qual os aspectos ontológicos do homem são compreendidos a partir de fatores fisiológicos, psicológicos e sociais, moldados pela vida mesma do indivíduo. Esse projeto combativo de Holbach configura-se assim nessas três frentes elementares. Nosso propósito aqui é esclarecer de forma mais detalhada esses três pontos de seu projeto filosófico.

0 primeiro ponto, portanto, versa sobre a crítica da moral tradicional, que tem em vista, principalmente, os princípios metafísicos e teológicos da vontade livre e do livre-arbítrio, pois 
associa a esses princípios um sistema jurídico e uma moral punitiva que, em vez de serem benéficos para os homens e à sociedade, são nocivos, já que não agem nas causas das ações e ainda as prejudicam. Isso ocorre porque exigem dos homens um total controle sobre os movimentos internos de seu corpo e um completo domínio das suas próprias ações, como se a causa dessas ações fosse sua própria vontade, isto é, uma vontade autodeterminada. Contudo, afirma Holbach, a vontade não é livre, mas, pelo contrário, ela é mobilizada por motivos, que são o querer algo e agir para possui-lo, ou o contrário, não querer e agir para evitá-lo: "não depende de nós impor ou remover os obstáculos que nos determinam ou nos detêm; o motivo que nos faz agir não está em nosso poder tanto quanto o obstáculo que nos detém, quer eles estejam em nós mesmos ou fora de nós" (HOLBACH, 2010, p.249).

Na perspectiva do filósofo, esse controle absoluto do ser humano sobre o mecanismo das suas ações é totalmente impossível, dada sua complexidade e à relação necessária entre suas paixões, suas ideias e os movimentos de sua vontade, que constituem uma estrutura sincronizada que não pode ser desfeita. Essa estrutura se deve à sua essência material, que é, pelas qualidades inerentes do homem, um ser que sente, deseja, pensa, quer e age. Todos esses movimentos são simultâneos e possuem todos uma mesma causa, ou um conjunto uniforme de causas conectadas. Assim, dizer que 0 homem age mal por escolher 0 mal quando poderia escolher 0 bem seria desconhecer ou ignorar o mecanismo "físico" que constitui o motor das suas ações. Conforme diz Holbach $(2015$, p.20), "Como todo homem nasce com algumas necessidades, nada é mais natural nele que o desejo de satisfazê-las. Suscetível de sentir o prazer e a dor, nada é mais natural que amar um e odiar outro. De onde se deduz que as paixões e os desejos são essenciais ao homem, inerentes à sua natureza, inseparáveis de seu ser e necessários à sua conservação".

\section{Blucher}




\section{Fábio Rodrigues de Ávila}

A partir disso, Holbach critica as instituições sociais que partem desses princípios fundamentados na metafísica e na dualidade matéria/espírito, e elabora uma crítica da organização social e das instituições políticas que têm por base essa moral tradicional: "Tratando da moral, não desçamos de maneira alguma ao fundo dos abismos de uma metafísica sutil ou de uma dialética tortuosa. Como as regras dos costumes são feitas para todos, devem ser simples, claras e demonstrativas, ao alcance de todos" (HOLBACH, 2015, p. XIX).

Em sua visão, os sistemas de leis existentes nas sociedades, apesar de suas mais variadas formas, levam sempre em consideração a capacidade dos homens de fazer escolhas, quando essa faculdade na verdade é inexistente. Os homens então são punidos sem necessidade por ações que a rigor eles não são responsáveis, e a punição por seus crimes praticados acaba por não surtir efeitos sobre a ocorrência dos crimes futuros, que voltam sempre a acontecer porque a causa original não foi modificada: "Pela negligência daqueles que governam os homens, pela imprudência, e frequentemente por sua má-fé, os costumes mais irracionais, as instituições mais aviltantes para os Povos, as injustiças mais acentuadas, desde que elas têm durado muito tempo, converteram-se em leis e conferem direitos" (HOLBACH, 1994, p.428). Uma vez sendo fundamentadas nas ideias imaginativas oriundas dos princípios metafísicos e teológicos, tais como aqueles de vontade livre e livre-arbítrio, as leis são ineficientes e as sociedades injustas porque não levam em conta a estrutura real da natureza humana, da qual devem derivar leis justas e princípios sociais funcionais.

Frente a esse sistema ineficiente, Holbach propõe uma moral erigida a partir dos princípios do materialismo, no qual o homem é tido como um ser de qualidades diversas, devido à diversidade dos elementos materiais que o compõe. Ele age de acordo com as causas contidas em 
seu interior, que é dado por alguns elementos como o grau de sua sensibilidade, o humor de seu temperamento, a força das suas paixões, a atividade de sua imaginação ou de sua razão: essas seriam as causas internas de sua atividade. Ao mesmo tempo, ele é influenciado pelos objetos que o circundam, pelo clima que modifica seu temperamento, pelos costumes que interferem em suas disposições, pelas leis que mobilizam suas paixões e tendências. Todos esses fatores constituem uma malha de relações causais que determinam uma imensa variação de desejos e necessidades inumeráveis. Nessa perspectiva, o homem é um ser pertencente à Natureza e todas as suas ideias, paixões e ações estariam sujeitas a um conjunto complexo de movimentos e de causas e efeitos interligados que são, a rigor, estritamente físicos. Jean-Claude Bourdin, por exemplo, afirma sobre o sistema de Holbach o seguinte:

Tudo nos homens é o efeito de causas insensíveis, em seus corpos, seus humores e, mais longínquo, nas moléculas sensíveis que os constituem, mas também de causas insensíveis constituídas das circunstâncias exteriores, feitas dos encontros improváveis e do que nós chamamos impropriamente de acaso e que não designa senão 0 emaranhamento das causas imperceptíveis (BOURDIN, 2006, p.338).

Disso decorre a sua concepção com relação à organização da sociedade. Como na Natureza, as moléculas de matéria com suas qualidades diversas se atraem e se repelem, dando origem a uma variedade de corpos organizados; do mesmo modo, um conjunto de homens com faculdades, ideias, desejos e paixões variados também precisa harmonizar-se para compor um corpo coletivo - político - coeso e estável. Contudo, essa variação é fonte também de divergências entre seus desejos e necessidades, o que acarreta conflitos sociais que precisam ser administrados para que os homens não se destruam uns aos outros. Desse modo, para propor um sistema moral e uma

\section{Blucher}


organização política que seja capaz de realizar o impulso primeiro da essência humana, que é buscar conservar-se e alcançar o bem-estar e a felicidade, é necessário investigar as singularidades dessa natureza humana e propor ideias que estejam de acordo com seus movimentos, faculdades e necessidades legítimos. Podemos assim afirmar, como o faz Bourdin, que o objetivo de seu sistema é "a felicidade dos homens, o desejo de preparar as bases da organização de uma vida social que assegure a felicidade de cada um dentro de instituições justas, racionais e duráveis, que repousem sobre ou derivem da Natureza sensível dos homens" (BOURDIN, 2006, p.330).

\section{0 conhecimento da natureza humana:}

Este é o segundo ponto de nossa investigação. Neste momento, vamos analisar a gênese do sistema moral proposto por Holbach, que é dada pela sua visão da natureza do homem. Como já dissemos, o homem é um ser material, que possui faculdades, ideias, desejos e paixões derivados do movimento das moléculas que o compõem. Em A Moral Universal, ele elabora uma profunda investigação das idiossincrasias humanas, procurando apontar as devidas causas da atividade do homem com relação a si mesmo - sua conservação e a busca de seu bem-estar - e com relação aos seus semelhantes - a vida coletiva:

0 homem é em toda parte um ser sensível, ou seja, suscetível de amar o prazer e de temer a dor: em toda sociedade, ele está rodeado de seres sensíveis que, assim como ele, buscam o prazer e temem a dor; esses últimos só contribuem para o bem-estar de seus semelhantes quando são determinados a isso pelo prazer que lhes é proporcionado; eles se recusam a contribuir a partir do momento em que lhes fazem mal (HOLBACH, 2015, p.XXVIII). 
Nossa análise procura mostrar como Holbach articula os conceitos de paixão, interesse e utilidade como sendo um mecanismo sincrônico que seria o motor da atividade. Assim, as paixões funcionam como mobilizadoras do interesse, pois impulsionam a vontade através dos desejos. 0 interesse, por sua vez, é o impulso primordial de autoconservação e busca do bem-estar. Ele é direcionado pelo que chamaremos de princípio de utilidade, que é a faculdade de julgar os objetos de acordo com os efeitos que eles causam no organismo, como uma sensação de prazer ou dor que desperta um sentimento de amor ou ódio por esses objetos. Esses três operadores formam um mecanismo que mobiliza a atividade e ao mesmo tempo dá um contorno às relações humanas, possibilitando para os homens a vida em comum.

Ele considera que, devido à sua natureza, o homem é um ser sociável, já que é incapaz de suprir todas as suas necessidades e sobreviver isoladamente. É por isso que a moral é necessária, pois a diversidade das qualidades dos homens e os conflitos que dela emergem requerem algum modo de regular essas relações, de maneira que são os deveres que o homem se propõe a realizar, através das ações que ele se prontifica a fazer e a evitar, que constituem os princípios da moral. Ele diz que "O homem é um ser sensível, inteligente, racional e sociável que, em todos os instantes, busca sem interrupção se conservar e tornar sua existência agradável" (HOLBACH, 2015, p.6). Assim, sem recorrer à metafisica - visto que ele parte da observação das ações humanas, e não de pressupostos a priori dados por uma revelação divina ou por uma razão suprassensível -, ele demonstra que o homem possui algumas qualidades inerentes à sua natureza, como a sensibilidade e a inteligência, e que é impelido a buscar o que the agrada e a fugir do que 0 ameaça, para assegurar sua autoconservação. As impressões que ele recebe dos objetos que são

\section{Blucher}




\section{Fábio Rodrigues de Ávila}

conformes à sua essência são-Ihe agradáveis, impelindo-o na direção deles, enquanto que as impressões que o afetam negativamente, ele as reprova, evitando os objetos que as causaram.

Esse mecanismo dá origem ao princípio da utilidade, pois aqueles objetos que proporcionam sensações agradáveis são considerados úteis, pois satisfazem as necessidades e contribuem para o bem-estar; já aqueles contrários, são considerados nocivos, pois perturbam 0 funcionamento do corpo e ameaçam a autopreservação. Desse modo, as paixões estão diretamente ligadas a esse princípio, pois elas são os movimentos intensos de amor ou ódio pelos objetos que se acredita serem úteis ou não, e necessários ou contrários ao bem-estar. Josiane Boulad-Ayoub, a respeito do papel das paixões na perspectiva do barão, afirma que "as paixões, para serem proveitosas, isto é, para que elas atinjam o resultado visado, manutenção ou maximização do bemestar, devem então ser orientadas pelo interesse ou mais precisamente pelo reconhecimento pelo cidadão do que constitui seu interesse: elas serão então consideradas úteis na medida em que elas permitirão a satisfação do desejo e a realização da felicidade" (BOULAD-AYOUB, 2006, p.266).

Vemos assim que as paixões inflamam o desejo, pois mobilizam a vontade e impelem 0 homem a agir, sendo essenciais para o impulso primordial da conservação de sua existência. Neste sentido, Holbach também afirma que as paixões não são em si mesmas boas ou más, já que são seus usos que as tornam úteis ou nocivas. Elas são necessárias ao homem por corresponderem à exigência da autopreservação. Isso se dá porque as necessidades dos homens em geral são as mesmas - alimentar-se, repousar, ter abrigo, etc. -, porém elas variam quanto aos meios de satisfazê-las, devido à variedade de paixões existentes. Essa variedade é decorrente da diversidade da natureza humana, pois a organização de cada indivíduo está sujeita às variações das circunstâncias de sua vida, como a época em que vive, o clima a que está habituado, a situação 
política, os costumes: todos estes são fatores determinantes que influenciam as paixões, pois geram desejos e necessidades específicos a cada indivíduo ou povo.

0 desejo, por sua vez, corresponde ao impulso em satisfazer esses desejos e essas necessidades. Ele está diretamente ligado ao interesse, que é o impulso de buscar aquilo que se julga imprescindível para a conservação e para o próprio bem-estar. 0 interesse é primordial para o homem, pois ele é o motor da vontade e da atividade na direção daquilo que proporciona a felicidade, e desse modo ele se liga às paixões e ao princípio de utilidade. 0 homem é afetado por um objeto, ele sente uma paixão por ele, julga seus efeitos e considera-o útil ou nocivo, e assim ele estabelece o laço entre esse objeto e seu bem-estar, e age de acordo com essa ligação. Segundo Pascal Charbonnat, "o materialismo de Holbach insiste na ligação entre os fenômenos físicos e morais. 0 interesse, fundamento natural da moral, representa o laço entre o ser sensível e o ser social. Ele explica os desejos, as repulsas do homem e sua tendência para viver em sociedade" (CHARBONNAT, 2007, p.359).

0 núcleo da doutrina moral defendida por Holbach é, portanto, esse mecanismo que engloba 0 interesse, o princípio da utilidade e as paixões. Esse mecanismo pode ser sintetizado em um sentimento, que ele chama de amor de si. 0 interesse, assim como as paixões, visa satisfazer esse amor que o homem tem por si mesmo. Ele é o desejo de conservar-se visando seu bem-estar; contudo, ele difere do egoísmo, que é um sentimento derivado da vaidade e do orgulho, que são considerados paixões viciosas ou nocivas. Já esse amor de si é um impulso sociável, pois considera o eu como um reflexo do outro, sendo indiscernível das relações sociais. Além do mais, o amor de si é um sentimento natural pois é necessário à autoconservação, e é devido a ele que o homem julga os seres com os quais se relaciona e os objetos dos quais faz uso.

\section{Blucher}




\section{Fábio Rodrigues de Ávila}

Na medida em que as paixões excitam um movimento na direção do objeto de desejo, e o homem, tendo conhecimento das qualidades desse objeto através da experiência, julga ser ele útil ou não para sua felicidade, 0 interesse 0 inclinará ou não a buscá-lo. 0 amor de si, portanto, inclina 0 homem a desejar apenas aqueles objetos que ele conhece e que ele julga necessários para sua felicidade, de maneira que ele ignora ou repele àqueles que julga nocivos ou que ignora as qualidades. Esse mesmo julgamento é feito com relação aos outros homens com quem ele compartilha a existência, de maneira que ele não estará disposto a agir virtuosamente para com aqueles que ele julga nocivos; porém, com relação àqueles que lhe são estimados, ele buscará sua estima através das ações virtuosas apropriadas. Ou seja, agir virtuosamente é o mesmo que ser útil aos outros, e para ser útil aos outros, é necessário, antes, amar a si mesmo: "Este amor por si, tão criticado por alguns moralistas e confundido despropositadamente por eles com um egoísmo insociável, não é, de fato, senão o desejo permanente de se conservar e de proporcionar a si mesmo uma existência feliz. Condenar o homem porque ele ama a si mesmo é censurá-lo por ser homem" (HOLBACH, 2015, p.29). Amor de si e virtude se veem, em Holbach, ligados de forma imperativa.

\section{A virtude - base da vida social e da moral:}

A passagem do físico para o moral se dá, assim, através do conceito de virtude. Ela é derivada dessa natureza material do homem que o impele a conservar-se e se torna uma exigência para a boa relação entre ele e seus semelhantes. Logo, impulsionado pela sua natureza a conservarse, 0 homem vê na virtude 0 instrumento mais adequado para a realização dessa inclinação.

Todas as relações sociais e afetivas têm por base 0 amor de si. Isso acontece porque 0 homem é um ser sociável, e é sendo útil aos seus semelhantes que ele atrai a estima deles. Ele 
observa o comportamento deles para consigo e julga-os a partir dos benefícios e dos danos que Ihe proporcionam. Na medida em que uns Ihe são úteis e tornam-se estimados, outros the são nocivos e tornam-se preteridos; a partir disso ele julga a si próprio e a seu comportamento com relação a eles. Ele avalia a si mesmo a partir dos outros, e 0 amor de si constitui-se a partir dessa estima e desse juízo. Do mesmo modo, também é o amor de si que condiciona à virtude, pois direciona o desejo de ser feliz tendo em vista ser estimado e querido, impelindo o homem a ser virtuoso, pois a experiência demonstra que é sendo útil aos seus semelhantes que eles quererão ser-lhes úteis reciprocamente: "No homem que reflete, o amor por si é sempre acompanhado de afeição pelos outros" (HOLBACH, 2015, p.32). Um homem sem esse amor de si seria incapaz de ligar-se devidamente aos outros, visto que ele desconfia de si e dos demais o suficiente para não estabelecer nenhum vínculo seguro com eles. Por essa razão, a moral deve, em vez de combater 0 amor de si, enaltecê-lo e mostrar que é amando a si mesmo que o homem pode, pelo seu interesse, ser bom e sociável. Contudo, naquele que o amor de si se sobrepõe a todos os sentimentos e à afeição que o homem pode ter pelos outros, esse sentimento torna-se um egoísmo solipsista, e ele torna-se necessariamente um ser insociável: "Aquele em quem o amor por si sufoca toda a afeição pelos outros é um ser insociável, um insensato que não vê que todo homem, vivendo com outros homens, está em uma completa impossibilidade de trabalhar pela sua felicidade sem a assistência dos outros" (HOLBACH, 2015, p.34).

A felicidade está, assim, diretamente relacionada à virtude. 0 homem erra por não perceber que ele não pode ser feliz sem 0 auxílio dos seus semelhantes, visto que ele tem necessidade deles, seja para satisfazer suas necessidades, seja para sentir sua própria existência. Logo, quando ele não se faz estimado, ele não poderá alcançar seu bem-estar, afinal, não sendo

\section{Blucher}




\section{Fábio Rodrigues de Ávila}

estimado, ele é preterido ou atrai a indiferença dos demais. Por outro lado, o homem que age virtuosamente é aquele que é útil para si mesmo e para os outros, preservando-se e auxiliando os outros em seu bem-estar. A virtude, portanto, é essencial, pois ela é a disposição que consiste nas ações que proporcionam um bem para quem as pratica e um bem para os outros aos quais elas afetam. Nisto está a singularidade do conceito conforme o designa Holbach: a virtude não consiste em sacrificar-se ou abster-se dos bens mundanos, como defende a tradição cristã, tampouco é um ardil ou uma sagacidade, como diz a tradição romana e Maquiavel, mas ela consiste justamente em proporcionar um bem para aqueles com os quais se compartilha a vida em sociedade, sem que isso implique em um ônus para aquele que proporciona esse bem. Já o vício é o oposto da virtude, é a ação que, empregada contra si ou contra os outros, causa um dano, prejudica ou ameaça a conservação e o bem-estar, e atrai, por conseguinte, o ódio ou a indiferença dos outros. A virtude implica, assim, uma prática constante, um hábito que serve para garantir aos homens os meios pelos quais eles satisfaçam seus desejos e busquem honestamente o quinhão da felicidade que Ihes é devida, sem com isso prejudicar a felicidade dos outros membros da sociedade.

É com base nesses princípios que ele rejeita absolutamente a liberdade da vontade como núcleo da sociabilidade e da moral e, principalmente, como princípio para o estabelecimento das leis e da justiça. A moral, conforme ele afirma, deve ser configurada a partir da essência material do homem, essência essa que é dada pela observação atenta das faculdades, das necessidades e principalmente das ações dos homens, de modo a rejeitar qualquer princípio que esteja pautado em ideias abstratas ou princípios puramente inteligíveis. A ciência, aqui, antecede a filosofia filosofia que se confunde com metafísica ou mesmo teologia: "Para ser universal, a moral deve ser conforme a natureza do homem em geral, ou seja, fundamentada na sua essência, nas 
propriedades e qualidades que se encontram constantemente em todos os seres da sua espécie, pelas quais ele é distinto dos outros animais. De onde se vê que a moral supõe a ciência da natureza humana" (HOLBACH, 2015, p.3). Ou seja, a partir da observação das nossas ações e de seus efeitos, descobrimos as suas causas de modo a poder modificá-las corretamente. Essa modificação é a base para a estruturação das leis e dos princípios da sociabilidade.

Isso é possível devido ao seguinte mecanismo. Sendo inteiramente material, o homem deseja e age de acordo com as necessidades internas de seu corpo, assim como a necessidade externa constituída pelas relações que ele estabelece com os outros corpos da Natureza, inclusive com os outros homens. Esse é o horizonte que conduz a sua investigação filosófica no âmbito da moral e da política. A partir da compreensão de que a Natureza é composta unicamente de matéria em movimento, o homem pode investigar a si mesmo e à sociedade na qual está inserido, para assim formular um juízo correto sobre a essência das suas relações, o que constitui o cerne da ciência moral e da ciência política. A ciência moral trata especificamente das relações dos homens entre si; já a política dedica-se à importância que as instituições morais, sociais e religiosas têm nessas relações: "De onde se vê que a moral não pode, sem maior perigo, se separar da Política, que é a arte de governar os homens reunidos em sociedade". (HOLBACH, 1994, p.247). Moral e política para Holbach são indissociáveis.

É nesse sentido que Holbach apresenta também a ideia de consciência moral. Apesar da carga espiritualista ou fenomenológica que esse conceito acarreta, o barão lhe dá um significado inteiramente materialista. Ele se configura do seguinte modo: da mesma maneira que julgamos os objetos, julgamos a nós mesmos e aos outros homens. Esse juízo que se faz do eu e do outro dá origem às ideias sobre a moralidade, as ações virtuosas e os vícios, sobre a conduta correta ou

\section{Blucher}




\section{Fábio Rodrigues de Ávila}

inadequada em relação aos desejos e sua satisfação. Essa consciência moral, que é derivada do exercício do julgamento, deve ser constituída principalmente pela educação e pelas leis. Ela é um dever do Estado ou do poder soberano, em suma, da organização política que funda a sociedade e estabelece suas normas. Um soberano negligente, que não Ihe dá acesso aos bens mais necessários para sua felicidade, está fadado a ter seus súditos desprovidos desse sentimento adquirido e sem essa consciência que inclina os homens a agir virtuosamente. Essa seria uma das principais causas do infortúnio nas sociedades, da degeneração dos costumes e da infelicidade generalizada entre os homens, dos quais decorrem os crimes, a violência e a desordem.

Um problema que se coloca é que, na medida em que as ações dos homens são determinadas pela sua natureza material, que visa necessariamente ao bem-estar, e 0 interesse impele à virtude e à vida social harmoniosa, qual a razão de existirem crimes, injustiças e arbitrariedades na maior parte das sociedades? Holbach responde que as sociedades são viciosas e os homens criminosos mais pelas condições desfavoráveis ao desenvolvimento das suas qualidades morais e sociais do que por sua própria responsabilidade ou por uma escolha deliberada na formação de seu caráter moral: "Quando dizem que o homem é um ser sociável, indicam assim que sua natureza, suas necessidades, seus desejos e seus hábitos o obrigam a viver em sociedade com os seres semelhantes a ele, a fim de se proteger com o auxílio deles dos males que teme e obter os bens necessários à sua própria felicidade" (HOLBACH, 2015, p.74).

As desigualdades e injustiças que são constantes nas sociedades são, por conseguinte, decorrências da História, e não, necessariamente, um problema ontológico, que remeteria a uma natureza humana degradada, decaída, conforme afirmam um Santo Agostinho ou um Pascal, tampouco de uma natureza humana perversa, como defenderiam mais tarde um Sade ou mesmo 
um Cioran. Sendo um problema histórico, a injustiça, a tirania e outros problemas de ordem política, assim como a degenerescência dos costumes, são uma consequência da forma como as sociedades acabaram por se organizar, seduzidas pelas ideias sugeridas de determinados indivíduos astutos que, à guisa de ideias fundamentadas na ignorância das leis naturais, instituíram uma ordem baseada em mitos, revelações e mistérios que asseguraram seu poder sobre os corpos e as consciências daqueles desprovidos do conhecimento dessas leis. Trata-se da crítica anticlerical e antirreligiosa que se encontra na principal obra de Holbach, o Sistema da Natureza, assim como em diversos outros textos, dedicados à crítica ao cristianismo, ao monoteísmo e até mesmo ao despotismo oriental - textos estes que escapam ao objetivo dessa nossa análise. Porém, é devido a essa influência do pensamento mítico e místico, das religiões reveladas e da relação entre governantes e sacerdotes que, conforme diz o barão, as sociedades ignoram as leis naturais, e as leis civis deixam de corresponder à natureza do homem, pois não basta apenas instituir leis que proíbem e punem determinadas ações, tampouco é suficiente inculcar na mente dos homens ideias que contrariam seus impulsos naturais. Essa forma de governar apenas acarreta essa condição de caos social, já que não age nas devidas causas das ações, não havendo assim um modo eficiente de sanar os problemas decorrentes desse modo de se estabelecer a ordem social. A única forma de solucioná-los é recuperar a perspectiva materialista da natureza humana, e fundamentar as leis e os costumes a partir de sua estruturação imanente.

Para isso, é imprescindível compreendermos o que Holbach entende por moral. Ele diz que "A moral é a ciência das relações que subsistem entre os homens e dos deveres que decorrem dessas relações; se preferirem, a moral é o conhecimento daquilo que devem necessariamente fazer ou evitar os seres inteligentes e racionais que queiram se conservar e viver felizes em

\section{Blucher}




\section{Fábio Rodrigues de Ávila}

sociedade" (HOLBACH, 2015, p.3). Sua proposta de moral e de sociedade visa, portanto, uma superação dessa visão equivocada da natureza do homem, uma moral liberada dos princípios metafísicos e teológicos da vontade livre e do livre-arbítrio, constituindo uma moral determinista, com base no princípio materialista da organização fisiológica, em que as paixões são tomadas como a principal ferramenta para os homens organizarem-se socialmente, a partir de um equilíbrio dos seus desejos que proporciona um ajuste das suas necessidades. Na medida em que os homens agem determinados por suas ideias e paixões, é a orientação destas que direcionará sua conduta à virtude ou ao vício, ao benefício ou ao dano de si mesmo e de seus semelhantes: "A boa consciência é a recompensa da virtude; ela consiste na segurança de que as nossas ações devem nos proporcionar os aplausos, a estima e a afeição dos seres com quem vivemos. Temos o direito de estar contentes com nós mesmos quando temos a certeza de que os outros estão ou devem estar contentes conosco" (HOLBACH, 2015, p.63).

Por meio dessa relação entre as paixões, o interesse e a utilidade, que delimita o caráter moral da virtude e forma a consciência moral do indivíduo, Holbach propõe a formação de uma sociedade não conflitante, mas harmoniosa, que visa a felicidade particular e, consequentemente, o bem-estar coletivo, pois os homens veem vantagem em auxiliar uns aos outros, em vez de ver a necessidade de competir entre si para atingir resultados particulares. A partir disso, é necessário formular um sistema jurídico no qual as leis procurem recompensar a virtude e punir os vícios, sempre tendo em vista o fortalecimento do corpo social enquanto um todo orgânico. Para isso, cada membro, sendo possuidor de direitos e deveres específicos, que o situe enquanto agente ativo na formação e organização social, não pode ser, por outro lado, 0 instrumento para o bemestar de outro sem que tenha em retribuição o seu próprio: "Os laços que unem os homens uns 
A etocracia de Holbach: Política e moral numa perspectiva materialista

aos outros não são senão as obrigações e os deveres aos quais eles estão submetidos de acordo com as relações que subsistem entre eles. Essas obrigações ou deveres são as condições sem as quais eles não podem se tornar reciprocamente felizes" (HOLBACH, 2015, p.3-5).

\section{O sistema político eudemonista de Holbach:}

A partir dessa concepção de natureza humana e de vida social, iremos agora para nosso terceiro e último ponto acerca do sistema de Holbach: investigar a perspectiva de sua filosofia política, tendo em vista as instituiç̧ões políticas que regem a sociedade e a vida coletiva, quais sejam, a função do poder soberano, o papel da educação na formação do cidadão e a instituição das leis e do sistema jurídico mais apropriado conforme a sua perspectiva de natureza huamana. Para Holbach, tanto a moral quanto a política são instrumentos que visam proporcionar aos homens uma existência harmoniosa com seus semelhantes, visto que, devido à diversidade da Natureza, os homens necessariamente são diversos, seus interesses são variados, e cada qual visa a um objeto de desejo e satisfação próprio que está de acordo com sua singularidade; isto, de certa forma, é a causa de inúmeros conflitos que precisam ser bem administrados pelo governo. Conforme afirma Paul Vernière, "[0 homem] não é moral porque obedece às crenças e às esperanças quiméricas de uma religião ou porque ele segue uma utópica lei natural, mas na medida em que ele colabora com a salvaguarda de uma sociedade que em retorno assegura sua felicidade: 0 amor ao próximo coincide com o interesse bem compreendido e o desenvolvimento harmonioso de cada um" (VERNIÈRE, 1954, p.638).

É possível identificar na filosofia de Holbach uma continuidade ontológica entre o homem físico - dotado de um corpo que sente, quer e age - e o homem moral - aquele que reflete, pondera

\section{Blucher}


suas ações e age em vista do melhor para si -, de modo que a antinomia razão/paixão é reconfigurada, de modo que a ordem da Natureza (corpo) e a ordem da Cultura (história, razão e civilização) estão submetidas a uma mesma lógica de funcionamento. 0 interesse pelo bem-estar, assim como a virtude que deseja o bem-estar alheio, associam-se num sincronismo político que configura a felicidade coletiva. As paixões não representam mais uma perturbação da ordem moral, pelo contrário, elas são tidas como um ponto de equilíbrio na relação do homem consigo mesmo e com os outros - em sua vida privada e sua vida social.

Propor aos homens uma moral universal fundamentada em princípios puramente abstratos ou transcendentes, contrários às suas paixões e que exigem que ele se desligue de sua própria natureza, é pedir para os homens incorrerem em crimes e arbitrariedades. As leis, desse modo, precisam ser regidas de acordo com a natureza do homem, levando em conta a diversidade de paixões e desejos que permeiam a multiplicidade de homens que se encontram na sociedade. Assim, a principal função dos soberanos configura-se em estabelecer as leis e normas que regulem a conduta dos membros do corpo social e político:

A autoridade do governo é justa porque ela tem como objetivo proporcionar a todos os membros da sociedade algumas vantagens que seus desejos irrefletidos, seus interesses mal-entendidos e discordantes, sua inexperiência e sua fraqueza os impediriam de obter por si mesmos. Se todos os homens fossem esclarecidos ou racionais, eles não teriam nenhuma necessidade de ser governados (HOLBACH, 2015, p.340-1).

Vemos assim a importância que Holbach atribui à função do poder soberano. Contudo, Holbach não é um defensor de uma monarquia absoluta - apesar de sua linguagem e terminologia política insistir na palavra príncipe -, pelo contrário, suas críticas são direcionadas principalmente 
à figura do déspota. Ele dedica alguns capítulos de La Politique Naturelle e Système Social ao tema da tirania e do despotismo, procurando demonstrar que são formas de governo injustas e que por isso não são legitimadas pela reciprocidade característica das relações naturais entre os homens, assim como em A Moral Universal ele condiciona a autoridade do soberano à justiça e à equidade que ele deve aos seus súditos, já que são eles que "permitem" que ele os governe. 0 soberano é uma figura central no sistema político de Holbach. Ele é quem regulará as relações e as associações feitas entre os homens, que se ocupará da elaboração e aplicabilidade das leis, ele será responsável pela educação do povo - que deve ser pública e universal - e estabelecerá as diretrizes necessárias para que cada cidadão usufrua tanto da sua liberdade política, da forma mais apropriada, quanto dos direitos da justiça e equidade, que lhe permitam empreender os meios necessários à sua felicidade, sem que incorra na obstrução da liberdade e da felicidade dos seus semelhantes.

Apesar de figurar como núcleo do sistema político, o soberano ainda não é o ponto central de seu pensamento. Nossa leitura compreende que o ponto central do sistema filosófico-político de Holbach está na sua proposta sobre o uso das paixões. Uma vez que elas em si mesmas não são boas ou más, e é sua utilidade e os efeitos que elas causam nos homens que Ihe atribuem um valor, cabe ao soberano estabelecer as leis que as orientem para o seu bom uso, ao mesmo tempo em que ele deverá coibir o uso nocivo ou abusivo de determinadas paixões, para que estas não prejudiquem a vida em sociedade, tampouco sejam nocivas para cada membro em particular.

Para exercer seus direitos sobre seus membros, a Sociedade Ihes deve a justiça, a proteção, as leis que asseguram sua pessoa, sua liberdade, seus bens: ela se encarrega de proteger-lhes de toda injustiça ou violência, de defender-lhes contra suas paixões recíprocas, de proporcionar-lhes o trabalho sem obstáculos ao seu bem-estar próprio e sem prejuízo ao dos outros; a colocar cada um sob a

\section{Blucher}


salvaguarda de todos, para fazê-los fruir em paz das coisas que eles possuem ou que eles têm justamente adquirido por seu trabalho, seus talentos, sua indústria (HOLBACH, 1994, p.233).

Um dos principais argumentos que Holbach utiliza ao elaborar seu sistema filosófico e político é o do interesse do príncipe na sua própria felicidade. É a partir de uma sociedade justa e feliz que ele pode dormir tranquilamente - lembremos que a questão do sono do soberano é uma temática tratada também por Hobbes - afinal, caso o soberano pretenda governar injustamente, tornando-se um tirano, ele não atrairá a estima e a consideração de seus súditos, mas, pelo contrário, será odiado por eles, o que põe em risco seu próprio poder. Portanto, caso ele queira preservar seu poder e sua posição, é de seu interesse que seu governo seja justo e suas leis sejam razoáveis para seu povo, pois desse modo ele será querido e governará com tranquilidade.

Os homens conferem tão alto valor ao favor de seus senhores, ficam tão perturbados com a ideia de desagradá-los, nós os vemos de tal modo diligentes em merecer a sua benevolência, que a virtude do príncipe é suficiente para fazer reinar em pouco tempo a virtude de seu império e para estabelecer com ela a felicidade pública, que será sempre a sua companheira (HOLBACH, 2015, 350).

Holbach considera, assim, a justiça e a equidade como virtudes primordiais. Elas são 0 núcleo da vida moral e social, pois devem aplicar-se a todos os âmbitos da vida do indivíduo: em suas relações familiares - entre um pai e uma esposa ou um filho -, em suas relações sociais - entre amigos, no comércio ou no trabalho -, nas relações econômicas - entre o rico e o pobre, entre os artesãos e industriais - ou nas relações políticas - entre o soberano e os súditos, entre os magistrados, legisladores e governantes junto ao povo - etc. A vida moral, social e política de todos os membros de um corpo político consolida-se a partir dessas virtudes. 
Não podendo nos estender mais nessa análise, por fim vemos que o barão francês é um pensador importante para a filosofia política de seu século. Nosso objetivo foi, através dessa breve análise, contribuir para sua divulgação, tratando-se de um pensador pouco conhecido do público brasileiro, mas também, e principalmente, auxiliar em uma melhor compreensão de sua filosofia e do pensamento materialista francês setecentista em geral.

\section{Referências Bibliográficas:}

BOULAD-AYOUB, Josiane. "L'homme de la raison future » et la politique naturelle des passions, In BOURDIN, J.C., (org.) Materialistes Français Du XVIIlle siècle: La Mettrie, Helvetius, Holbach, Paris : PUF, 2006, p.255-268.

BOURDIN, Jean-Claude. Introduction, In Materialistes Français Du XVIIle siècle: La Mettrie, Helvetius, Holbach, Paris : PUF, p.251-254, 2006 (Colection Fondements de la politique).

. Le matérialisme de Holbach pour « sortir » de la philosophie?, In Materialistes Français Du XVIIle siècle: La Mettrie, Helvetius, Holbach, Paris : PUF, p. 325-352, 2006 (Colection Fondements de la politique).

CHARBONNAT, Pascal. Histoire des philosophies matèrialistes, Paris : Éd. Syllepse, 2007.

HOLBACH, Barão de. A Moral Universal ou os deveres do homem fundamentados na sua natureza, tradução Regina Schöpke, Mauro Baladi, $1^{0}$ Ed. - São Paulo : Martins Fontes, 2015 - (Coleção Tópicos).

Sistema da Natureza ou Das Leis do Mundo Físico e do Mundo Moral (Système de La Nature ou Des Lois Du Monde Physique et Du Monde Moral), tradução Regina Schöpke, Mauro Baladi, $1^{\circ}$ Ed. - São Paulo : Martins Fontes, 2010 - (Coleção Tópicos).

. La Politique Naturelle ou Discours sur les vrais principes du gouvernement par un ancien magistrat, Paris : Fayard, 1998.

. Système Social ou príncipes naturelles de la morale e la politique avec um examen de I'influence du gouvernement sur les moeurs, Paris : Fayard, 1994.

VERNIÈRE, Paul. Spinoza et la Pensée Fraçais avant la Révolution, Paris : PUF, 1954.

\section{Blucher}

